\title{
PRAAT - USO, USABILIDADE E APLICAÇÃO
}

\author{
Andérbio Márcio Silva Martins* \\ André Luis Azambuja Alves** \\ Fábio Pereira Couto***
}

\begin{abstract}
RESUMO: Neste artigo, buscamos evidenciar a importância do Praat para análise acústica da fala, tomando como exemplo alguns estudos linguísticos de línguas indígenas brasileiras, tais como Oliveira (2017), Couto (2016), Ivo (2014) e Nascimento, Maia e Couto (2016). Apresentamos uma análise do Praat, no que se refere ao grau de usabilidade do software, considerando os critérios propostos por Nielsen (1993), quais sejam: (a) Facilidade de aprender; (b) Eficiência; (c) Memorização; (d) Erros e (e) Satisfação. Por fim, demonstramos uma aplicação prática de um dos recursos disponíveis no Praat para a análise acústica de segmentos vocálicos. O procedimento de análise do Praat foi realizado a partir de análise de dados da língua Guarani Ñandéva, falada no sul de Mato Grosso do Sul, com foco de investigação na vogal alta central [i]].
\end{abstract}

PALAVRAS-CHAVE: Usabilidade. Software Praat. Línguas Indígenas Brasileiras. Guarani Nhandéva

ABSTRACT: In this paper, we seek to highlight the importance of Praat for the acoustic analysis of speech, taking as example some linguistic studies of Brazilian indigenous languages, such as Oliveira (2017), Couto (2016), Ivo (2014) and Nascimento, Maia and Couto (2016). We present an analysis of the Praat, considering the degree of usability of the software, taking the criteria proposed by Nielsen (1993), which are: (a) Ease of learning; (b) Efficiency; (c) Memorization; (d) Errors and (e) Satisfaction. Finally, we demonstrate a practical application of one of the resources available in Praat for the acoustic analysis of vowel segments. The analysis procedure of the Praat was carried out from the analysis of data from the Guarani Nandéva language, spoken in the south of Mato Grosso do Sul, with focus of the investigation on the central high vowel [i]].

KEYWORDS: Usability. Software Praat. Brazilian indigenous language. Guarani Nhandéva

\section{INTRODUÇÃO}

A fala é um objeto de investigação de muita complexidade, vinculada a várias questões típicas de suas realizações no meio social. Nesse sentindo, e em busca de melhorar as possibilidades de análise e de entendimento da fala, foram criados vários instrumentos de análise, principalmente com o advento do avanço tecnológico. Entre esses avanços, foi criado o programa de análise acústica denominado de Praat, que é um software para realizar reconhecimento de fala das realizações físicas dos correlatos da fala humana, tendo a fonética experimental como metodologia e técnica de investigação. $O$ desenvolvimento do software partiu do holandês Paul Boersma, o qual necessitava de um programa específico para auxiliar a pesquisa de doutorado voltada à área da fonética acústica na Universidade de Amsterdam, no início dos anos 1990. Nessa época, o 
linguista e desenvolvedor de softwares, David Weenink, uniu-se ao projeto para desenvolver/programar ${ }^{1}$ esse sistema de análise física da fala.

Conforme Boersma (2001), as melhorias que vêm sendo implementadas tornaram o Praat um dos softwares com algoritmos capazes de trazer mais exatidão em inúmeras situações de análise acústica, notadamente para atender certos objetivos de linguistas pesquisadores em análises acústicas e articulatórias dos sons, com fins descritivos que corroboram estudos de interpretações fonológicas das línguas. Esse software pode ser executado em vários sistemas operacionais ${ }^{2}$ e tem característica de ser gratuito e livre ${ }^{3}$.

No site dos idealizadores do Praat, há uma lista com as versões ${ }^{4}$ de atualização, contendo uma pequena síntese das melhorias implantadas ou descartadas na versão atual do software e respectiva data de lançamento. Cabe destacar que, apesar das atualizações, não houve mudanças na interface do programa que o torne de fácil aprendizado no primeiro contato. Na verdade, ele continua exigindo conhecimento em programação, caso o pesquisador/programador necessite melhorar as rotinas de análise por meio dos scripts de programação no próprio software. Contudo há muitos usuários que compartilham esses scripts, o que permite maior possibilidade de uso por parte de pesquisadores com menor conhecimento em programação.

Dependendo da área e da língua pesquisada, alguns estudiosos conseguem adaptar-se à customização do software definida em um script feito por outro pesquisador e alcançar o próprio propósito de pesquisa. Inicialmente, todavia, nota-se que alcançar os objetivos de análise acústica com o Praat não é uma tarefa fácil, principalmente para quem não tem familiaridade com programação, já que a própria interface do software não é muito intuitiva. Pois, além do programa exigir conhecimento linguístico por parte do pesquisador e um conhecimento relativo da língua pesquisada, é necessário conhecimento em programação para particularizar suas ações de pesquisa e tornar a análise mais detalhada, precisa e otimizada.

O primeiro impacto diante dessa ferramenta tecnológica para um pesquisador iniciante, mesmo que o programa seja de fácil aceitação dos pesquisadores brasileiros, é a dificuldade de inserção de palavras, sintagmas e orações no programa de áudio para, então, alcançar a análise segmental dos sons que os constituem, por meio do espectrograma apresentado. Este, por sua vez, é a representação da forma da onda de uma fonte sonora, uma justaposição de sons, e não propriamente a sua segmentação, o que se revela um problema de análise acústica, justamente porque o objeto de análise apresenta uma realização contínua de segmentos sonoros entre o início e o término da produção

\footnotetext{
${ }^{1} \mathrm{O}$ Praat foi desenvolvido na linguagem de programação $\mathrm{C}$ e posteriormente foi atualizada para linguagem $\mathrm{C}++$.

${ }^{2}$ Pode ser instalado em diferentes Sistemas Operacionais: Windows, Mac, Linux, FreeBSD, $\underline{\text { SGI, }} \underline{\text { Solaris. }}$

${ }^{3}$ Um software gratuito e livre alicerça-se em quatro liberdades fundamentais, quais sejam: executar o software sem restrição de uso; analisar as funcionalidades para possíveis adequações de uso; redistribuição de cópias e de cópias modificadas e/ou atualizadas (Fonte: https://www.gnu.org/philosophy/freesw.en.html).

${ }^{4}$ Disponível em: 〈http://www.fon.hum.uva.nl/praat/manual/What_s new .html>. Acesso em: agosto de 2018 .
}

INTERLETRAS, ISSN N 1807-1597. V. 9, Edição número 34. Outubro, 2021/ Março de 2022- p. 
articulatória. Esse contexto, como afirmam Barbosa e Madureira (2015), leva a uma dificuldade de demarcação da barreira entre um som e outro, considerando ainda a possibilidade de certas propriedades acústicas de determinados sons influenciarem a produção de outros sons, tanto em ambientes livres e/ou determinados. Tal demarcação ocorre necessariamente de forma manual, baseando-se na interpretação visual do pesquisador a despeito do espectrograma gerado, revelando, em princípio, uma decisão, em alguma medida, subjetiva, tornando difícil estabelecer separação precisa dos segmentos. De acordo com Kent e Read (2015), a fala corresponde a um conjunto de elementos fonéticos, cuja limitação exata entre eles é trabalhosa porque depende da percepção acústica do usuário/pesquisador.

Neste artigo, portanto, demonstramos a importância do Praat para análise acústica da fala, a partir de alguns estudos linguísticos de línguas indígenas brasileiras: Oliveira (2017), Couto (2016), Ivo (2014) e Nascimento, Maia e Couto (2016). Em seguida, realizamos uma análise do Praat, quanto ao grau de usabilidade do software. Foram considerados os seguintes critérios: facilidade de aprender, eficiência, memorização, erros e satisfação, conforme Nielsen (1993). Por fim, apresentamos uma aplicação prática de um dos recursos disponíveis no Praat para a análise acústica de segmentos vocálicos. Para tanto, fizemos uso de dados da língua Guarani Ñandéva, falada no sul de Mato Grosso do Sul, com foco na vogal alta central [i]. A essas seções, seguem as considerações finais e as referências bibliográficas dos estudos que fundamentaram este artigo. Destaca-se que este artigo é uma apresentação revisada e ampliada de alguns dos resultados alcançados por Alves (2019) em sua dissertação de mestrado, defendida no Programa de Pós-Graduação em Letras da Universidade Federal da Grande Dourados.

\section{O USO DO PRAAT EM PESQUISAS COM LÍNGUAS INDÍGENAS BRASILEIRAS}

O volume de pesquisas publicadas sobre os sons da fala que utilizam o software Praat como ferramenta metodológica de análise é expressivo. Muitos livros de ampla aceitação nacional e internacional o citam nas pesquisas de análise acústica, como também em outras áreas pertinentes ao estudo da fala humana, como em Boutsen e Dvorak (2015). A predileção sobre o uso dessa ferramenta pode ser explicada por alguns motivos: o livre acesso ao software sempre atualizado diretamente pelo site ${ }^{5}$ dos desenvolvedores; a ampla aceitação do software em razão de ter um dos algoritmos de maior precisão para análise da fala, conforme Boersma e Heuven (2001), e uma quantidade de tutoriais de uso do programa disponíveis no próprio site e em fóruns de discussão.

Todavia, ainda são muito escassas as pesquisas publicadas sobre produção e percepção da fala de línguas indígenas brasileiras com o auxílio de um software desenhado especificamente para essa função, como o Praat. Uma hipótese acerca disso é que o pesquisador, além de necessitar de um bom conhecimento teórico e metodológico em fonética e fonologia, necessita de um bom manejo no uso do software para estabelecer o

\footnotetext{
${ }^{5}$ Disponível em: http://www.fon.hum.uva.nl/praat/.
} 
andamento da pesquisa. Destaca-se que o Praat não possui uma interface de fácil aprendizagem sem uma série de treinamentos referente aos recursos que a ferramenta disponibiliza para análise do sinal acústico da fala.

De todo modo, identificamos algumas pesquisas que lançaram mão do software para entender melhor os aspectos fonéticos e fonológicos de uma língua indígena específica. Como bem advogam Hayward (2000) e Ladefoged (2007), os foneticistas cada vez mais vêm utilizando algum instrumento tecnológico para testar ou comprovar as suspeitas na investigação da fala em razão de muitos aspectos serem inacessíveis apenas de oitiva. Entre as pesquisas que consultamos, fizemos o seguinte recorte dos trabalhos que julgamos importantes por utilizarem diversos recursos do Software Praat: Oliveira (2017), Couto (2016), Ivo (2014) e Nascimento, Maia e Couto (2016). Nesta seção, apresentamos alguns dos procedimentos de análise adotados pelos pesquisadores supracitados com uso dessa ferramenta em pesquisas com diferentes línguas indígenas brasileiras.

\subsection{OLIVEIRA (2017)}

O trabalho de Oliveira se refere a uma dissertação de mestrado sobre os aspectos sociolinguísticos e fonológicos da língua Kinikinau, pertencente à família linguística Aruák. Nesse trabalho, entre outros objetivos, o pesquisador propõe uma revisão de alguns aspectos da fonologia da língua Kinikinau descrita anteriormente por Souza (2008), que havia levantado a hipótese de que o Kinikinau pudesse ser considerada uma língua tonal. Os pressupostos para essa característica parecem não se sustentar a partir do estudo realizado por Oliveira (2017). O que o levou a verificar a hipótese estabelecida por Souza (2008) foi o fato de a língua ter sido considerada tonal a partir de uma avaliação perceptiva auditiva dos alongamentos das vogais e da tendência de tonicidade desses fonemas aparecer à esquerda da palavra. Além disso, de acordo com Oliveira, Souza parece não levar em conta o traço prosódico. Dessa forma, Oliveira (2017) propõe a verificação do fenômeno por meio da análise acústica da língua subsidiada pelo software Praat. A análise é realizada na mesma perspectiva estabelecida por Couto (2016), que estuda outra língua da mesma família do Kinikinau, a Língua Manxineru. Assim, o TextGrid foi segmentado em quatro níveis: Fonético, Fonológico, Morfológico e Tradução. Vale ressaltar que o programa permite colocar vários níveis conforme o objetivo e necessidade do pesquisador/usuário. 
Figura 1 - Espectrograma da palavra ['u:ti] 'nós'

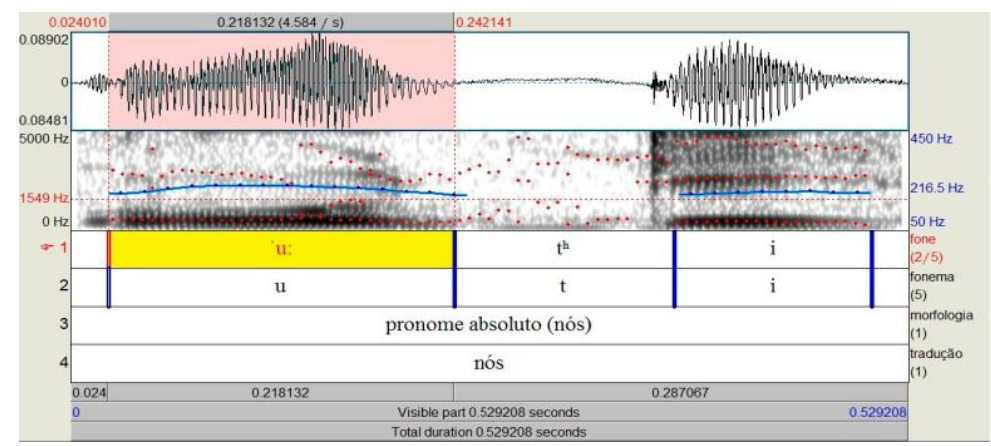

Espectrograma de banda larga ilustrando o correlato acústico do alongamento da vogal/u/ na palavra ['u:ti] 'nós'.

Nessa análise, é demonstrado, a título de exemplo do que foi descrito pelo autor, o alongamento da vogal [u:], conforme o entendimento de Souza (2008). Todavia, conforme Oliveira (2017), esse alongamento com perda do seu contorno tonal não é suficiente para caracterizar uma língua tonal. Dessa maneira, são demonstrados valores da frequência do pitch dessa vogal. Segundo Oliveira (2016, p. 95), "pitch médio de [u:] é de 216,470 Hz. O pitch máximo é de 229,024 Hz e o pitch mínimo é de 192,734Hz.", os valores indicam que a vogal não carrega um contorno tonal significativo para indicar essa proeminência. Cabe ressaltar que somente com o auxílio da ferramenta Praat, o pesquisador conseguiu reunir provas para demonstrar que a hipótese de o Kinikinau ser uma língua tonal não se sustenta. Para Oliveira (2017), lançar mão de uma ferramenta e técnica da fonética acústica possibilitou a ele testar com maior clareza não apenas a sua hipótese sobre o fenômeno estudado como também refutar outra hipótese a qual não utilizou desta ferramenta. Nesse sentido, e nesse recorte, fica clara a importância do software para confirmar ou desfazer algumas hipóteses de investigação de uma língua, principalmente nas línguas indígenas brasileiras.

\subsection{COUTO (2016)}

Em sua tese de doutorado, Couto (2016) buscou realizar uma descrição dos aspectos prosódicos da língua indígena Manxineru por meio da acústica experimental. Entre muitos recursos tecnológicos e metodológicos utilizados para compor a pesquisa de Couto, ele elegeu o software Praat para esclarecer fenômenos fonéticos e morfológicos dessa língua, como apagamento vocálico, aspiração, desvozeamento e vozeamento, mudança entoacional, ressilabificação, além da harmonização e da vocalização, os quais acarretam combinações entre prefixos pessoais e nomes, o que promove, em muitos casos, alterações fonéticas e fonológicas nas palavras. Entre esses fenômenos fonéticos investigados por Couto (2016), escolhemos para nossa análise de exemplificação a metodologia com uso do software Praat para identificar o "apagamento vocálico". 
Para identificar o fenômeno do apagamento vocálico, o pesquisador estabeleceu uma exposição metodológica para uso do Praat muito bem detalhada, entre algumas orientações, a disposição dos TextGrids (as caixas para inserir textos), a leitura dos espectrogramas, as medidas dos formantes e a duração das vogais. Tal procedimento pode servir de parâmetro para outras pesquisas em línguas indígenas.

Figura 2 - Espectrograma da palavra [n: 'tiwle] 'meu pulmão'

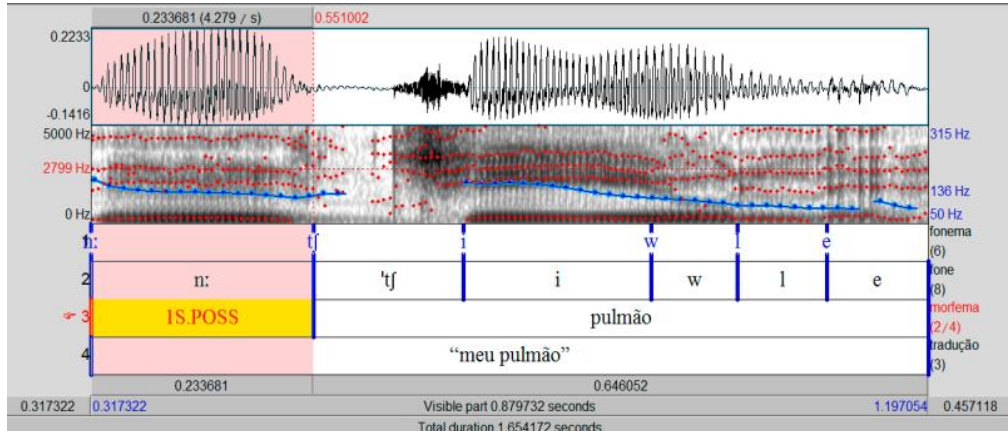

Espectrograma de banda larga ilustrando o correlato acústico do apagamento da vogal [o] do prefixo pessoal possessivo de primeira pessoa do singular/no/ da palavra [n:' 'fiwle] 'meu pulmão'.

Figura 3 - Espectrograma da palavra [n:ti'wine] 'meu sal'

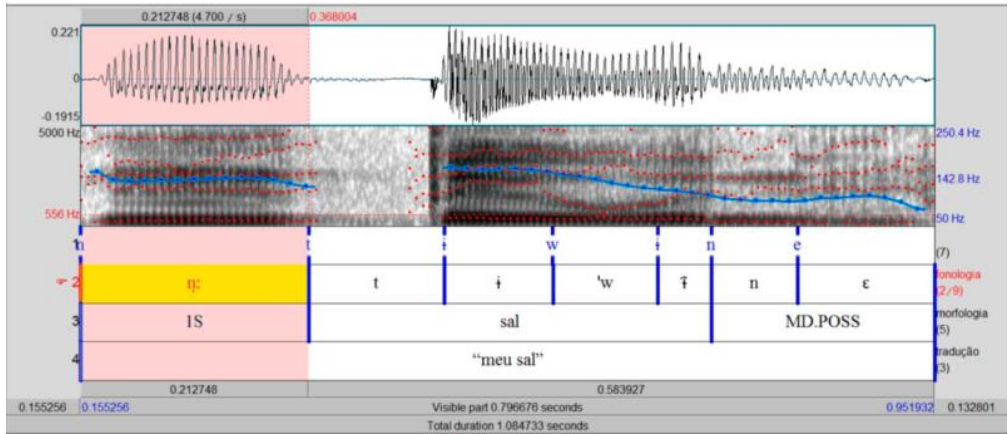

Espectrograma de banda larga ilustrando o correlato acústico do apagamento da vogal [o] do prefixo pessoal possessivo de primeira pessoa do singular/no/ da palavra [n:ti' wĩne] 'meu sal'.

Com base em dados da língua com uso da fonética acústica, da ferramenta Praat e com ilustrações como descrito nas figuras precedentes, o objetivo do pesquisador foi demonstrar, por meio de medidas acústicas do Praat, o fenômeno de apagamento vocálico de morfemas pessoais como o \{no- $\}$. Diante desses dados coletados, Couto (2016) demonstrou que há a deleção, na superfície, das vogais e que o som [n] e outros, na língua Manxineru, sofrem um processo de apagamento, o que leva o pesquisador a refutar os postulados de Mattesson (1965), que afirmava ter consoantes silábicas na língua Piro, que é a variante da língua Manxineru, falada no Peru, já que ele demostra, por meio dos espectrogramas, que há o enfraquecimento da vogal a ponto de ela, em alguns casos, ser 
deletada, mas afirmando que isso é só no nível fonético e que ocorre em regiões delimitadoras de segmentos sonoros.

Conforme verificado, os resultados obtidos por Couto (2016) com o uso fundamental da ferramenta Praat, ao demonstrar com detalhes a intensidade dos formantes vocálicos - os quais permaneciam inacessíveis somente pela avalição perceptiva auditiva - trouxeram novas perspectivas sobre a língua Manxineru. Diante do exposto, entendemos a importância de a análise acústica ser realizada com um software adequado.

\section{$1.3 \operatorname{IVO}(2014)$}

Em sua dissertação de Mestrado, Ivo investigou as características fonéticas do GuaraniMbyá, variedade falada na aldeia Paraty Mirim, na cidade de Paraty do estado do Rio de Janeiro. A pesquisadora, ao levantar na literatura as características fonéticas do Mbyá, percebeu divergências sobre a organização do sistema fonológico dessa língua. Esse impasse era exatamente sobre a baixa produção de sons fricativos. Dessa maneira, ela optou por uma análise acústica, justamente pelo caráter objetivo dessa área, com propósito de reduzir as interferências subjetivas que levaram a considerar o GuaraniMbyá com alta produtividade de sons fricativos.

Para realizar essa análise, primeiramente, a autora da dissertação faz uma conceituação desses sons fricativos. E traz dois exemplos de uma palavra fricativa labiodental não vozeada [f] e a produção da fricativa labiodental vozeada [v] do português brasileiro.

Figura 4 - Espectrograma da palavra ['faka]

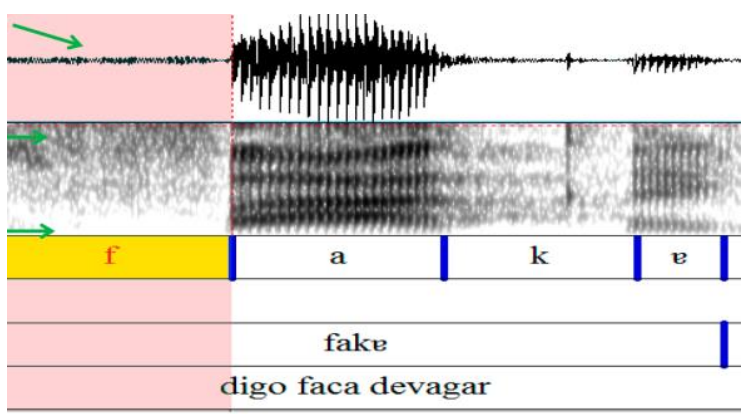

Espectrograma de banda larga ilustrando o correlato acústico da realização da fricativa desvozeada [f], na palavra ['faka], no contexto da frase-veículo 'digo faca devagar'. 
Figura 5 - Espectrograma da palavra ['vaka]

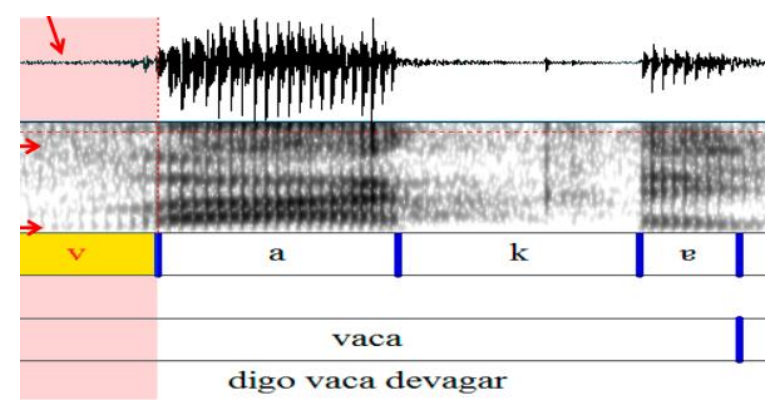

Espectrograma de banda larga ilustrando o correlato acústico da realização da fricativa vozeada [v], na palavra ['vaka], no contexto da frase-veículo 'digo vaca devagar'.

Pelas imagens, percebe-se uma demonstração dos efeitos acústicos das fricativas labiodentais reproduzido nos oscilogramas e espectrogramas do Praat. Pelas setas indicadas, há a demonstração do ruído inicial de ondas aperiódicas da produção das fricativas indicadas. Algo que também poderia ser colocado pela autora seria o uso do pitch, uma vez que essa medida demonstra com mais clareza a diferença entre as duas fricativas, já que esse sinal verifica a ausência ou não de vozeamento.

\subsection{NASCIMENTO, MAIA E COUTO (2016)}

Este trabalho refere-se a um estudo que buscou evidenciar Tempo e Evidencialidade - na perspectiva Psicolinguística Experimental -, em duas categorias gramaticais na língua Kaingang, família Jê do Tronco Macro-jê. Primeiro, realizaram um experimento em um grupo de verbos de flexão prosódica com fito de entender qual seria a característica que distinguiria o tempo passado e futuro, e, também, foi aplicado um teste perceptual para reconhecer se uma flexão melódica estaria exercendo o traço de flexão gramatical. No aspecto da Evidencialidade, eles investigaram como os falantes nativos interpretam algumas partículas evidenciais, $m \tilde{y} r$ - informação visual interpretada, je para informação reportada e vã para consequência frustrada de uma ação. Dessa forma, eles buscaram entender como essas partículas estariam fornecendo pistas sobre os aspectos cognitivos.

Segundo os autores, a língua Kaingang é catalogada na literatura como uma língua acentual e apresenta uma característica peculiar de flexão prosódica no tempo. Pode-se dizer que verbos finalizados em segmento vocálico realizam flexão morfológica, já os verbos finalizados em segmentos consonantais não admitem flexão morfológica. Essa inflexão é demonstrada pelo software Praat na frequência fundamental F0, tanto no passado como no futuro. 
Figura 6 - Curva fundamental da frase 'fóg ag ty nãn kãtá nugnur'

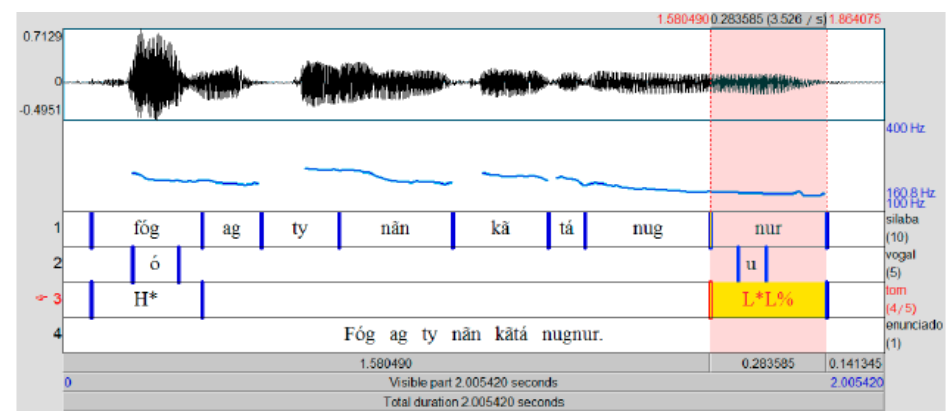

Forma de onda e curva de pitch, demostrando a análise entoacional da frase declarativa 'fog ag ty mãn kãtá nugnur'.

Figura 7 - Curva fundamental da frase 'fóg ag my nãn kãtá nugnur?'

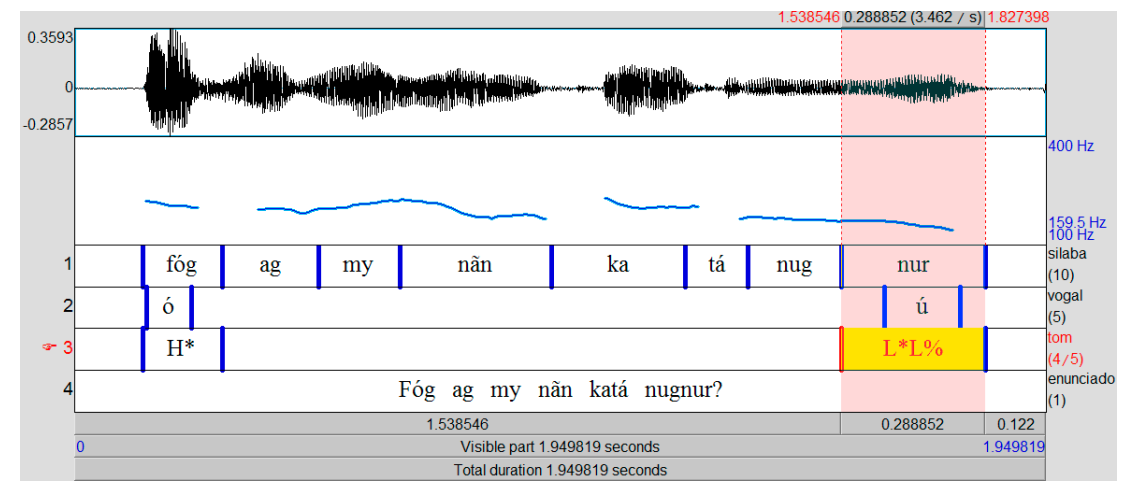

Forma de onda e curva de pitch, demostrando a análise entoacional da frase interrogativa 'fog ag ty mãn kãtá nugnur?'.

Com esse experimento, é possível verificar que os autores buscaram demarcar a entonação por meio da análise da onda de pitch. Dessa forma, demonstraram os contornos que contrastam entre uma declarativa ou interrogativa no futuro. Vale salientar que, com essa mesma metodologia, conseguiram também demarcar os contornos de marca temporal no passado.

\section{A USABILIDADE DO PRAAT}

Do ponto de vista de Styler (2017), embora existam informações técnicas referentes à atualização frente a inúmeros bugs que podem ocorrer nesse software, tais como o aprimoramento do algoritmo para análise do sinal acústico, na maioria dos casos ela não agrega a finalidade de tornar o uso dessa ferramenta mais prática em razão de ainda não apresentar uma interface que prime ser mais intuitiva ou que favoreça uma melhor interação com o usuário. Por conta disso, há fóruns de discussões, tutoriais disponíveis pela internet, algoritmos que podem ser instalados pelos scripts do próprio software 
disponibilizada nas páginas de dois pesquisadores ${ }^{6}$ da área de fonética e fonologia. Todavia, essas questões de usabilidade não afetam a importância desse programa no meio acadêmico. Segundo Boutsen \& Dvorak (2015, p. 78): "Praat é um software muito conhecido para investigação fonética e acústica, com recursos voltados à análise espectral, identificação de formantes, rastreamento de pitch, entre muitos outros ${ }^{7}$."

Nesta seção, propomos a análise de um dado acústico específico da língua Guarani Nhandéva falada no sul de Mato Grosso do Sul para avaliar a facilidade e a experiência de uso do software Praat, seguindo cinco critérios elaborado por Nielsen (1993), quais sejam: Facilidade de aprender, Eficiência, Memorização, Erros e Satisfação.

Para chegarmos a esse objetivo, escolhemos, metodologicamente, seguir as orientações de Sadowsky (2017), mas com alguns critérios técnicos de análise aplicados por Couto (2016), para análise da língua Manxineru. O pesquisador em questão, entre algumas demonstrações de análise no Praat, elencou quatro níveis de intervalos no TextGrid para realizar a análise de transcrição, como: o morfológico, o fonológico, o fonético e a tradução da palavra. Dessa maneira, colocamos as diretrizes de análise de avaliação heurística estabelecido por Nielsen (1993) para avaliar os passos que demos para estabelecer o início da análise de um segmento.

É importante destacar que essa análise foi realizada com as funções básicas de uso desse software, aquelas encontradas nas primeiras páginas de tutoriais sobre o programa, para quem está tendo o primeiro contato com ele, tais como: janela de análise e inserção de elementos sonoros; análise oscilográfica (forma de onda), análise espectrográfica, segmentação e rotulagem de áudio com uso dos TextGrids. Há outras funções ${ }^{8}$ que não contemplamos nessa análise, quais sejam: Análise espectral (FFT); Análise espectral (LPC); A análise da curva melódica; Suavização da curva melódica; Estilização da curva melódica; Análise da curva de intensidade; e Análise de espectro médio (LTAS).

Para chegar ao TextGrid são necessários alguns passos (Figura 8). Primeiro selecionar o arquivo LongSound e, em seguida, clicar em annotate para abrir a caixa de diálogo e selecionar "To TextGrid", para, enfim, apresentar "Tier Names". Esse é um recurso para estabelecer os intervalos em forma de caixa a fim de inserir elementos textuais conforme o critério de análise estabelecido pelo pesquisador. Um dado importante dessa captura de imagem do Praat é o tutorial para construir os TextGrid em "Annotation Tutorial".

${ }^{6}$ Disponível em: http://sadowsky.cl/software-es.html, Scott Sadowsky. Acesso em: agosto de 2018.

Disponível em: http://wstyler.ucsd.edu/praat/ Will Styler. Acesso em: agosto de 2018

${ }^{7}$ Praat is a wll-known application designed for phonetic and acoustic analysis, with features for such tasks as spectral analysis, formant identification, pitch tracking, among many other.

8 Disponível em: http://www.fon.hum.uva.nl/praat/manual/Intro.html; http://bibliotecadigital.caroycuervo.gov.co/998/. Acesso em: setembro de 2018.

INTERLETRAS, ISSN N 1807-1597. V. 9, Edição número 34. Outubro, 2021/ Março de 2022- p. 
Figura 8 - Janela Objects no Praat (ALVES, 2019)

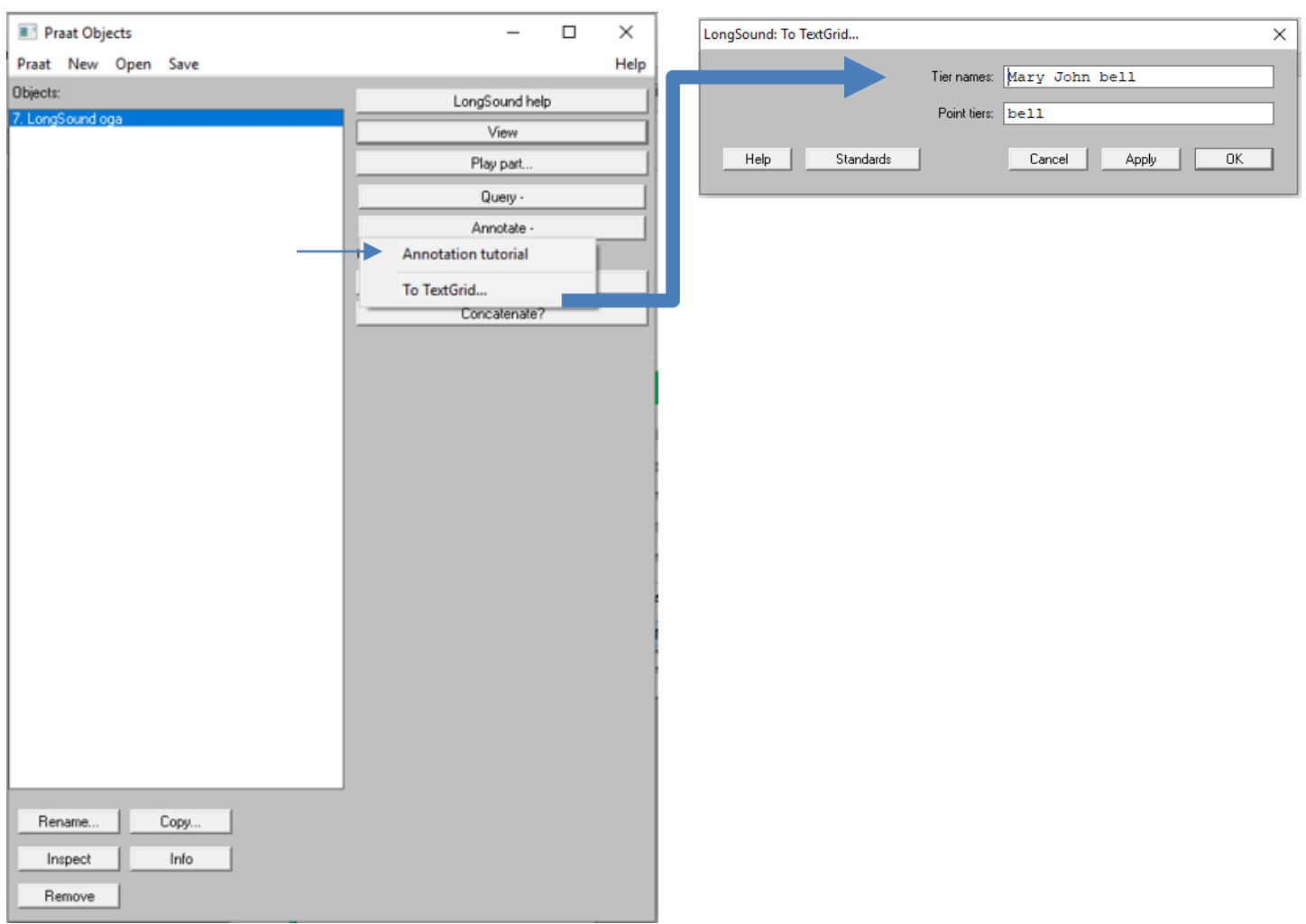

Conforme estabelecemos, iremos segmentar em 4 intervalos os TextGrids. Dessa maneira, serão organizados em: Fonética, nível 1; Fonologia, nível 2; Morfologia, nível 3 e Tradução da palavra nível 4. Observe a caixa de diálogo com ordem dos níveis, na figura 9:

Figura 9 - Janela TextGrids na área de inserção de criação dos níveis de análise no Praat (ALVES, 2019)

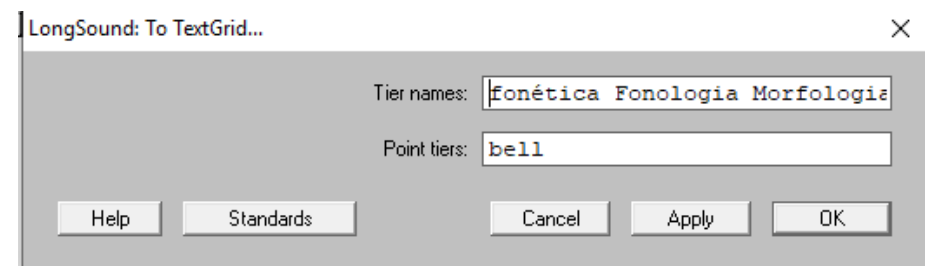

Após a inserção dos nomes nos níveis dos intervalos das caixas de texto, o software apresenta a principal interface de análise para um dado de um segmento sonoro. É representado dentro de Objects o TextGrid da palavra a ser analisada. Nesse arquivo, conforme assevera Sadowisk (2017), o TextGrid já aparece destacado, conforme é possível observar na figura 10. Essa é uma outra complicação do software, que pode não atender alguns critérios de avaliação de um teste heurístico. $O$ arquivo não é salvo 
automaticamente, é necessária a seleção dos dois arquivos para termos a representação do gráfico do som e das caixas de texto para sinalizar os critérios de análise. Podemos encaixar essa situação em três ou mais critérios da avaliação heurística, entretanto, escolhemos: visibilidade do estado do sistema, pelo motivo de o software não informar ao usuário para salvar esse arquivo; prevenção de erros, já que se não for selecionado os dois arquivos, ou não ser informado pelo sistema esse passo a ser tomado pelo usuário, teremos que fechar a janela e reabri-la. E por conta dessa última situação, podemos aferir o teste heurístico do controle e liberdade do usuário. Essa diretriz orienta o usuário a avaliar se o software permite sair de uma situação de equívoco de forma rápida, sem necessitar restabelecer a tarefa por um caminho mais demorado (BARBOSA e SILVA, 2010). No Praat não há possibilidade de reverter alguns passos equivocados realizados pelo usuário na construção dos Textgrids, a não ser por alguns scripts construídos ou adaptados para essa função.

Figura 10 - Janela TextGrid demostrando os níveis (tiers) de análise para segmentação no Praat (ALVES, 2019)

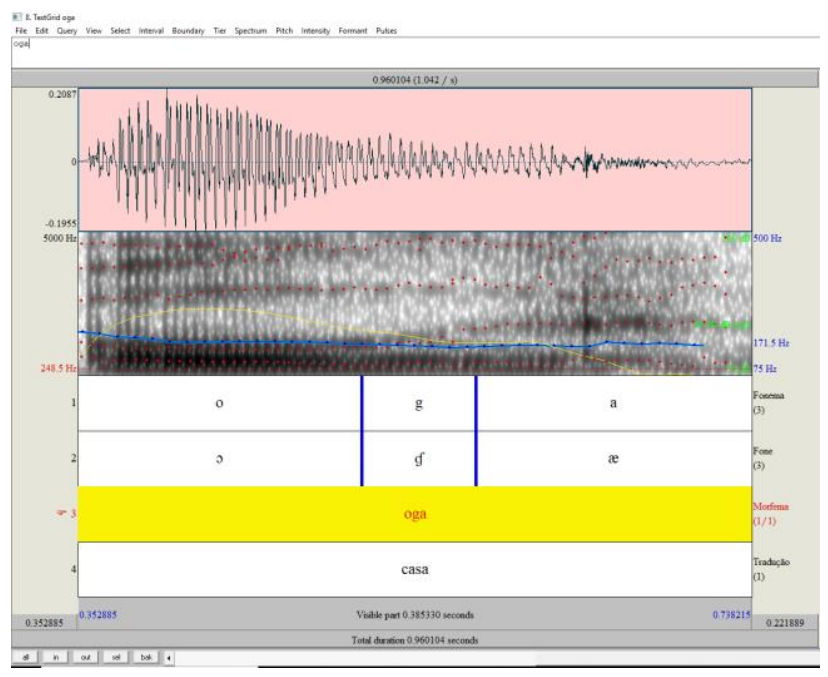

Ao realizar todos os processos da forma adequada, com os níveis de transcrição estabelecidos na metodologia de análise, pode-se dizer que é a parte onde começa a análise do segmento sonoro. Conforme Styler (2017), essa é a interface na qual o pesquisador passará a maior parte do tempo interagindo com o software Praat para realizar medição e análise fonética.

Em nosso exemplo, há som, mas considerado ruído, no início do segmento que adicionamos. Dessa maneira, podemos ajustá-lo pela seleção do segmento com o mouse, orientamo-nos pela disposição do oscilograma e pelos ícones dispostos na parte inferior esquerda, como em "sel". Essa parte é fundamental porque pela audição e pela visualização do oscilograma é que serão realizadas as distinções das pistas acústicas: "vogais, fricativas, nasais, oclusivas, africadas, líquidas, ditongos, semivogais "(KENT e READ, 2015). Vê-se, por isso, que a importância de estabelecer uma metodologia de 
análise é um passo importante. Em últimas palavras, há que se ter um bom critério na seleção do corpus de uma língua com vistas aos fenômenos dessa língua que serão investigados.

Após configurarmos o TextGrid, conforme o método de pesquisa proposto, realizamos uma inspeção da interface do Praat com objetivo de testar sua usabilidade em um contexto prático de uso, examinando a interface com base nos princípios heurísticos reconhecidos de usabilidade. Ainda assim, pode ocorrer divergências quanto à satisfação e à eficiência de um determinado sujeito em operar a ferramenta em avaliação, pois se trata também de uma percepção subjetiva. Essa depende muito do grau de familiaridade com a ferramenta em teste. Dessa forma, identificar os problemas de uso prático com base nas diretrizes de avaliação heurística depende muito dos objetivos traçados para análise do software. Todavia, por mais que exista algumas divergências, muitos detalhes de usabilidade podem ser contemplados por todos que usam a ferramenta porque essa atividade mostra uma atividade prática no uso do software. Nesse contexto, buscamos realizar essa tarefa em um período de, no máximo, duas horas. Conforme destaca Barbosa e Silva (2010), sessões muito longas interfere na qualidade da avaliação, tendo em vista o cansaço de muitas repetições e testes realizados dentro de um período de tempo.

Visibilidade do estado do sistema: em todas as fases de uso desse software não há informação se a atividade realizada foi bem-sucedida, não há um sinal ou ícone que indique o status da ação. Dessa forma, o software simplesmente não avança com ação ou oferece algum determinado erro que não pode ser imediatamente corrigido pelo usuário.

Correspondência entre o sistema e o mundo real: as ferramentas disponibilizadas no Praat exigem conhecimento prévio para estabelecer o uso adequado. Todavia, as informações trazidas pelos ícones do software não aparecem em uma ordem que facilite a execução de uma determinada atividade. Uma possibilidade é colocar ícones que sinalize melhor as tarefas, com cores diferentes, que chama a atenção do usuário. Atentamos para essa questão no momento que organizamos os níveis (tiers) para determinar a segmentação do áudio. Houve muita dificuldade para demarcar e corrigir um elemento inserido de forma equivocada. Enfim, todas as atividades exigem um passo cuidadoso para não cometer algum erro e ter de recomeçar o trabalho novamente.

Controle e liberdade do usuário: já mencionamos esse critério, o Praat não permite desfazer equívocos de forma intuitiva. Diante de qualquer erro, o software não oferece uma saída para correção. E isso toma muito tempo de pesquisa de análise em um único segmento sonoro.

Reconhecimento em vez de memorização: as instruções de uso do Praat não são visíveis facilmente. $\mathrm{O}$ uso da ferramenta exige memorização e um constante uso, uma vez que são facilmente esquecidas. Na interface, não há ícones que simbolize uma tarefa de forma clara. Dessa forma, ao passar para uma outra tarefa fica difícil se orientar considerando quais foram os passos realizados na tarefa anterior.

Consistência e padronização: o software não estabelece alguns ícones com as convenções de design que já vislumbramos em outras aplicações. Quem observa as operações comuns, que normalmente podem ser encontradas em design de outras aplicações, a 
simples tarefa de voltar uma tarefa não é viável, pois não há essa função no software. Um exemplo: podemos segmentar com um mouse um segmento de áudio mediante a uma linha vertical com pontos cinzas e estabelecer as fronteiras de cada elemento acústico do som a ser analisado. Mas, se ocorrer algum equívoco nessa demarcação, não aparece de forma simples a opção de retirá-la. O usuário precisa clicar no traço de demarcação, usar a tecla de atalho alt+backspace para retirar a demarcação ou ir até o menu e navegar até a solução para esse problema.

Flexibilidade e eficiência de uso: a tarefa de estudar a área de fonética acústica exige conhecimento teórico e prática de análise. $\mathrm{O}$ fato é que alguns pesquisadores possuem um conhecimento avançado, tanto teórico quanto prático da ferramenta. $\mathrm{O}$ problema que não se pode deixar de evidenciar é o caso dos usuários e pesquisadores novatos, pois eles buscam a ferramenta para poder aplicar o conhecimento. Nesse caso, o software não permite uma interação suficiente e eficaz para o iniciante, já que a interface não oferece recursos que possibilita o aprendizado rápido de uma dada tarefa.

Projeto estético e minimalista. A principal janela do Praat oferece um projeto minimalista, são apenas alguns botões para selecionar, abrir o áudio e outros para criar os Textgrids. Contudo, a criação do Textgrid exige uma série de cliques e digitação de texto. Poderia ser um processo mais simples, com possibilidade de uma rápida customização, para facilitar, ao usuário iniciante, a utilização dessa ferramenta.

Prevenção de erros: o Praat tem um grande problema por não atender esse critério, diferentemente de outras aplicações, como editores de textos e planilhas. Ele não salva automaticamente o trabalho realizado nele, se ocorrer algum erro e o usuário não salvar manualmente, o trabalho de análise se perde. Há essa possibilidade por meio de scripts, mas depende de o usuário entender a linguagem scripting para poder realizar esses ajustes, algo que não é comum a uma boa parcela dos usuários do Praat.

Ajude os usuários a reconhecerem, diagnosticarem e se recuperarem de erros: na análise desse segmento da palavra óga (casa) do Guarani Nhandéva, aconteceu algumas mensagens de erro ao tentarmos apagar um nível colocado equivocadamente. O software não especifica de forma clara que tipo de erro está ocorrendo. Apenas informa códigos da linguagem técnica de construção do software. E o usuário não consegue entender qual erro foi cometido.

Ajuda e documentação: o Praat oferece essa opção em "Help". Todavia, as informações podem não ser muito claras para quem é iniciante no uso do programa. Cabe salientar que existem fóruns ${ }^{9}$ e sites ${ }^{10}$ que disponibilizam tutoriais para tentar capacitar quem inicia as tarefas de análise acústica com o software.

Com isso, concluímos que, em termos de Usabilidade, o Praat é um programa que impõe ao usuário uma atividade prática constante a fim de que se familiarize com sua forma de ser operado, sendo, portanto, pouco intuitivo. Por todas essas razões, compromete o uso de quem está iniciando os estudos de fonética acústica. É importante considerar que os

\footnotetext{
${ }^{9}$ Disponível em: https://uk.groups.yahoo.com/neo/groups/praat-users/info. Acesso em: março de 2019.

${ }^{10}$ Disponível em: http://www.domingo-roman.net/manual_analisis_acustico.html; http://wstyler.ucsd.edu/praat/. Acesso em: março de 2019.
}

INTERLETRAS, ISSN N 1807-1597. V. 9, Edição número 34. Outubro, 2021/ Março de 2022- p. 
estudos da fala dependem de ferramentas tecnológicas como esse software. Daí a constatação de que ele deveria ser mais intuitivo para quem está iniciando os estudos da fala. Contudo, mesmo assim, é inegável a sua importância para o desenvolvimento de análises acústicas.

\section{APLICAÇÃO - ANÁLISE ACÚSTICA DOS FORMANTES DA VOGAL CENTRAL ALTA [f]}

Para apresentarmos alguns parâmetros de análise das vogais, vale a pena ressaltar, inicialmente, os estudos do engenheiro sueco Gunnar Fant em sua obra "Acoustic theory of speech production" sobre Teoria Fonte-Filtro da produção da fala. Nesses estudos, Fant (1970) apresentou um esquema físico e matemático de circuito elétrico para representar a produção da fala. Mediante a uma fonte de energia gerada pelas pregas vocais e o trato vocal como um modulador acústico dessas frequências. Segundo Barbosa e Madureira (2015), a fonte sonora gerada pode situar em qualquer espaço entre a glote e os lábios e, em consequência, o trato vocal funcionaria como um corpo que favorece algumas frequências sonoras. No que diz respeito a essa teoria, as vogais são produzidas sem nenhuma resistência ao ar. As características acústicas da produção dos sons das vogais são mais simples e diretas se comparadas às consoantes. Dependem apenas do fluxo de ar e a fonte sonora das vibrações das cordas vocais. Um atributo importante para análise acústica das vogais são as frequências das ressonâncias do trato vocal denominadas formantes. De acordo com Ladefoged (2007), os principais formantes para análise das vogais são o primeiro formante, $\mathrm{F} 1$, responsável pela altura do corpo da língua. O segundo formante, F2, está atrelado ao avanço e recuo da língua. O terceiro formante, F3, referese ao arredondamento dos lábios.

Diante dessas constatações, o objetivo da análise é identificar as características acústicas do primeiro formante ( $\mathrm{F} 1)$ para comparar com as frequências da vogal central alta [i] no mesmo segmento de palavra e de uma frase selecionada do Guarani Nhandéva. Decidimos por esse critério ao examinarmos um rol de cem frases gravadas para esta pesquisa. Nessas análises, constatamos que a vogal [i] é uma característica muito peculiar da língua indígena Guarani Nhandéva, ao compararmos com as qualidades vocálicas encontradas em português e em espanhol, línguas também faladas pelos Guarani que se encontram no sul de Mato Grosso do Sul.

Propusemos, então, verificar os picos de ressonância da vogal mediante às frequências dos respectivos formantes da vogal central alta [i] no início de palavras. Para isso, utilizamos o recurso do Praat denominado FFT $^{11}$ - sigla em inglês, para Transformada Discreta Fourier. Esse método foi desenvolvido para realizar uma adaptação da teoria de Análise de Frequências denominada Fourier, desenvolvida pelo matemático Jean-Batiste Joseph Fourier. A teoria de Fourier apontava as ondas periódicas como decomposição infinitas de ondas senoidais. Essa constatação matemática trouxe benefícios para as pesquisas sobre o som, uma vez que seria possível desenvolver um espectro, um desenho

\footnotetext{
${ }^{11}$ Fast Fourier Transform.
}

INTERLETRAS, ISSN N 1807-1597. V. 9, Edição número 34. Outubro, 2021/ Março de 2022- p. 
temporal da onda sonora em período de frequências. Todavia, conforme advoga Kent \& Read (2014), os sons da fala são quase periódicos porque terminam em uma série de tempo contínuo. E pela análise da Teoria de Fourier não poderia ser descrito um sinal aperiódico ou quase periódico por todo o tempo. Além disso, seria muito trabalhosa e de difícil aplicação matemática nos computadores. Dessa maneira, foi desenvolvido um algoritmo de análises digital de sinais sonoros denominado a Transformada Discreta Fourier (FFT -Fast Fourier Transforma). A escolha dessa técnica é bastante recomendada para análises de pequenos segmentos sonoro, tal como uma vogal. Esse método permite colher informações muito específicas das frequências dos formantes e amplitude presentes em determinado ponto de uma fonte sonora (STYLER, 2017).

Dessa maneira, nosso propósito é demonstrar, em detalhes, as etapas para alcançar uma análise dos segmentos fonéticos da palavra yvaga, da composição yvaga pytũ 'entardecer', via análise da Transformada Discreta de Fourier e empreender as análises do resultado alcançado. Portanto, a análise constituirá em observar a vogal central alta [i] no início de palavra.

Inicialmente, criamos um Textgrid no Praat para nos orientar na análise do segmento acústico da frase yvaga pytũ pela análise FFT.

Figura 11 - Janela TextGrid na segmentação da sentença yvaga pytũ no Praat (ALVES, 2019)

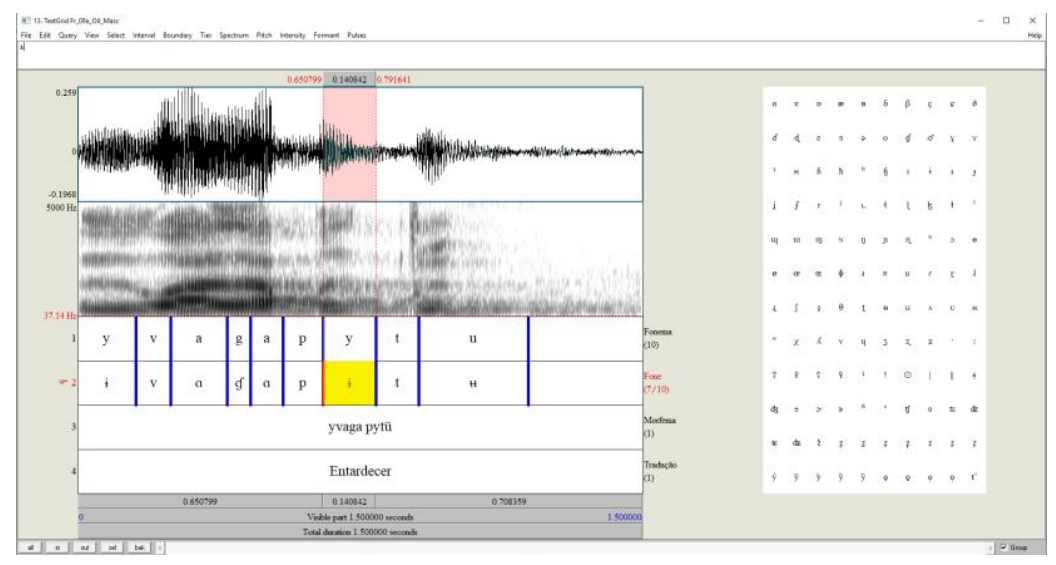

Para facilitar a Usabilidade do software, implementamos um script ${ }^{12}$ com o alfabeto fonético internacional (IPA) ao lado direto da Figura 11. Esse script são textos em linha com instruções dadas ao software para adequar ou, como nesta rotina de pesquisa, instalar o alfabeto fonético ao lado dos Textgrid. Em nossas análises das frases facilitou muito a inserção dos "fones" porque oferece uma orientação para delimitar um segmento fonético que se pretende analisar, como a demarcação da vogal central alta [i] em suas ocorrências no mesmo segmento de palavra. Os frutos desse processo serão alcançar a representação do espectro FFT e observar/comparar a amplitude via os picos de ressonância entre essas vogais (SILVA, SEARA, et al., 2019).

${ }^{12}$ Coletamos esse script em https://github.com/stylerw/styler_praat_scripts. Acesso 25/05/2019

INTERLETRAS, ISSN $N^{o}$ 1807-1597. V. 9, Edição número 34. Outubro, 2021/ Março de 2022- p. 
Ao clicar na tecla View \& Edit, como sinalizada pela seta azul, abrirá a janela com uma onda oscilógrafa em cima e o espectrograma abaixo, conforme demonstrado na Figura 13. Por meio dessa caixa de diálogo, algumas ações serão estabelecidas até alcançarmos a análise da relação da vogal nasal com a oral, mediante a análise espectral FFT.

Figura 12 - Janela Praat Objects no Praat (ALVES, 2019)

I. Praat Objects
Praat New Open Save
Objects:

Figura 13 - Janela ampliada do oscilograma e espectrograma da onda sonora da vogal [i] no objeto Spectrum no Praat (ALVES, 2019)

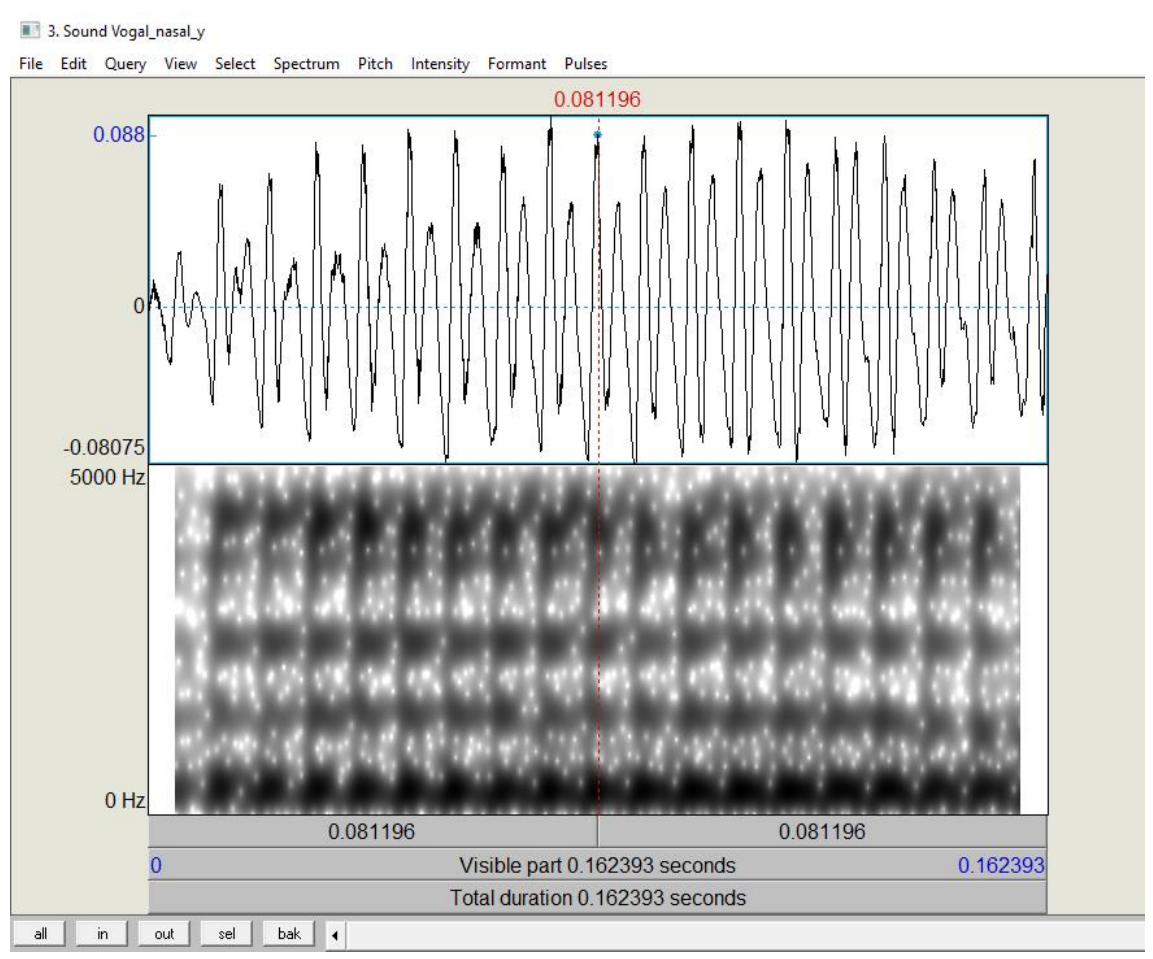

Diante da janela Spectrum, inicialmente, precisa-se selecionar um ponto no espectrograma. De acordo com Silva (2019), cada ponto corresponde a um ciclo glotal (vibração das pregas vocais). A melhor forma, portanto, é selecionar um ponto central da vogal no espectrograma em razão de existir maior estabilidade no segmento. Observe a linha vermelha tracejada na figura 13. Ela está dividindo a vogal no meio. Dessa maneira já está adequada para obter a partir de um pulso glotal o espectro da análise FFT. Após

INTERLETRAS, ISSN N 1807-1597. V. 9, Edição número 34. Outubro, 2021/ Março de 2022- p. 
esse ajuste, é preciso, também realizar algumas adequações com as seguintes operações: a) acionar a aba Spectrum; b) ir até Spectrogram settings... e, finalmente, e) observar as configurações, conforme demonstrado na Figura 14.

Figura 14 - Janela Spectrum em que se visualiza o local de ajustes possíveis no Praat (ALVES, 2019)

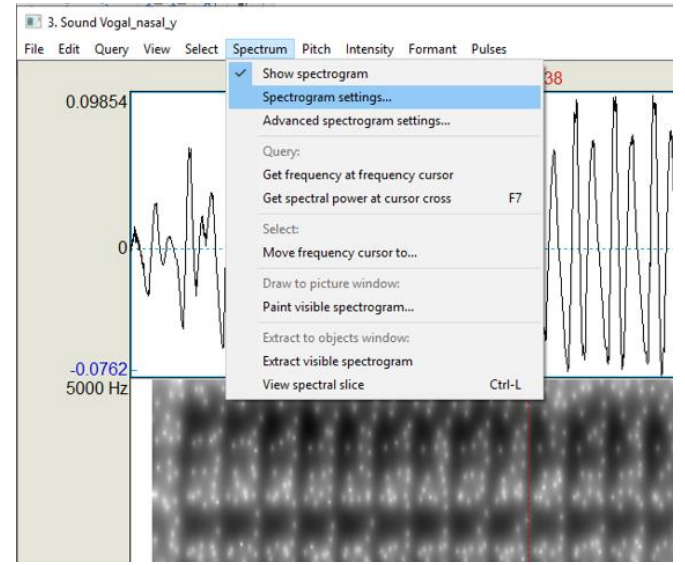

Figura 15 - Janela Spectrogram settings em que se visualiza o local de ajuste de banda de análise no Praat (ALVES, 2019)

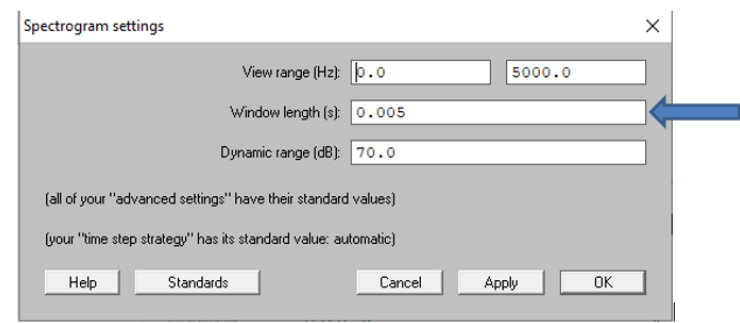

Ao observamos a Figura 15, percebemos que o Praat por padrão apresenta uma janela de análise 0.005 (ms) de banda larga, adequada para análise da ordem temporal de parte de uma faixa sonora e para visualizar os formantes ${ }^{13}$ das vogais, por exemplo (STYLER, 2017).

Após confirmarmos esse ajuste, na aba Spectrum, selecionamos a View spectral slice para visualizarmos as características espectrais FFT na primeira vogal oral alta [i] e, posteriormente, no segmento da vogal oral baixa [a] da palavra yvyga com espectro FFT, conforme ilustram as figuras 16 e 17.

\footnotetext{
${ }^{13}$ Os formantes são pontos específicos de frequências nos sons da fala e visualizados nas faixas horizontais no espectrograma (CRISTÓFARO, Thaïs. Dicionário de Fonética e Fonologia. São Paulo: Contexto, 2017. p. 120).
} 
Figura 16 - Janela Spectrum em que se visualiza o local de ajuste dos espectrogramas no Praat (ALVES, 2019)

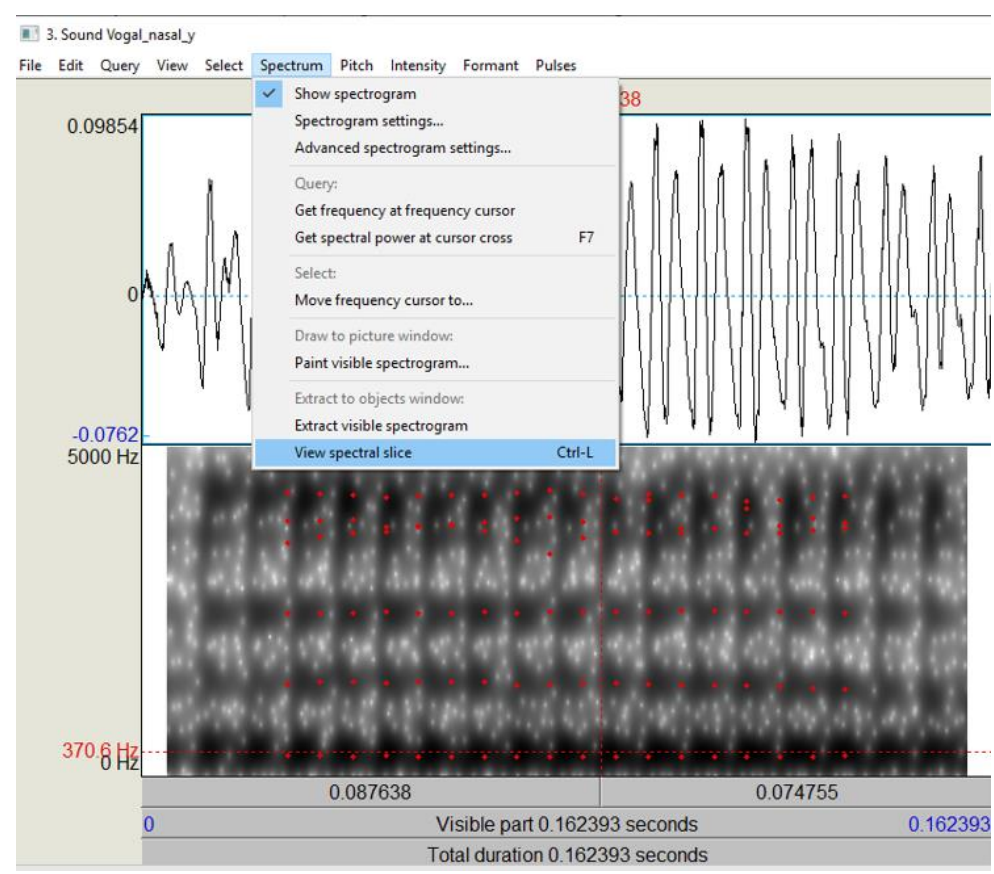

Figura 17 - Janela em que se visualiza os dados dos formantes e da amplitude da vogal [i] no Praat (ALVES, 2019)

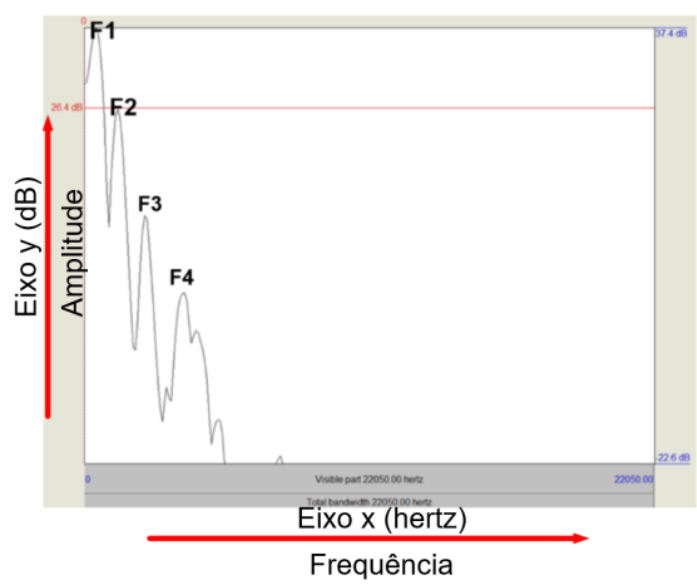

Formantes da vogal central alta da Figura 17

Inicial [i] da palavra yvagapytũ

Altura dos formantes de [i]: F1 $=280.726 \mathrm{~Hz}, \mathrm{~F} 2=1442.418 \mathrm{~Hz}, \mathrm{~F} 3=2511.411 \mathrm{~Hz}$

Duração de $[\dot{\mathrm{i}}:]=0.08119 \mathrm{~ms}$

INTERLETRAS, ISSN N 1807-1597. V. 9, Edição número 34. Outubro, 2021/ Março de 2022- p. 
O Espectro FFT apresenta a amplitude no eixo vertical y $(\mathrm{dB})$ e frequência no eixo horizontal x (Hertz). Conforme constata Silva (2019), os valores das amplitudes são caracterizados por uma maior altura no início e um enfraquecimento no final.

De acordo Kent \& Read (2015, p. 62):

\begin{abstract}
O primeiro formante é tipicamente o mais intenso, principalmente pela interação com as amplitudes dos outros formantes. Uma forma de pensar sobre isso é dizer que o F1 caminha nas caudas das frequências baixas das outras curvas de formantes de modo que F1 é reforçada em amplitude em comparação com os outros formantes.
\end{abstract}

Pela análise do espectro da Figura 17, com a aplicação da transformada inversa de Fourier (FFT), fica mais claro visualizar a amplitude. Uma interpretação possível é que a amplitude de F1 cai à medida que as frequências dos formantes F2, F3, F4 aumentam. Esse fenômeno pode ser evidenciado ao se usar a sequência Query $\rightarrow$ Get cursor. Inicialmente, é necessário que o cursor do mouse esteja no pico do formante desejado para obter a frequência e clicar em Get cursor para observar a frequência correspondente dos formantes.

\title{
CONSIDERAÇÕES FINAIS
}

O software Praat tem sido um importante instrumento para análise de dados acústicos nas línguas indígenas brasileiras. Observamos nas pesquisas de Ivo (2014); Silva (2011); Oliveira (2017); Couto (2016) e Nascimento, Maia e Couto (2016) que essas pesquisas, conforme foi demonstrado, lançaram mão do Praat ao analisar o sinal acústico de uma língua indígena brasileira, confirmaram fenômenos e também encontraram características na língua antes não documentadas. Daí a importância desse ramo de ciência auxiliado pela interface da tecnologia para ajudar a descobrir, afirmar ou contrapor hipóteses. Ademais, Ladefoged (1996) alerta que até os maiores especialistas em fonética podem não conseguir realizar uma análise apenas pela percepção auditiva com base apenas na experiência linguística e conhecimentos fonéticos. Por isso, um software com os recursos de análise torna-se importante.

Durante o uso da ferramenta, encontramos algumas dificuldades com a interação inicial do software, conforme demonstramos ao longo deste trabalho. Mas isso não tira o mérito dos parâmetros acústicos que podem ser alcançados com o uso da ferramenta Praat. Percebemos, também, que uso do software precisa estar alinhado com a experiência do pesquisador. Tentamos usar alguns scripts, mas percebemos que alguns foram desenvolvidos com ajustes para outras línguas e seria trabalhoso adequá-los aos nossos propósitos. Escolhemos ajustar manualmente, conforme os ensinamentos de Madureira e Barbosa (2015); Kent \& Read (2014); Silva (2019); Couto (2016). Como bem destaca Styler (2017), mesmo que se encontrem um script para montar um Textgrid automático, a tarefa de segmentar um dado acústico depende do trabalho perceptual do pesquisador. 
Neste trabalho, também apresentamos uma metodologia (FFT) em detalhes para usar um dos inúmeros recursos que o software Praat oferece e pudemos confirmar, mediante os dados colhidos, a informação já consolidada na doutrina em relação à inversa da frequência F1 com altura da língua. É importante ressaltar que gravamos as frases na língua Guarani Nhandéva apenas utilizando um gravador digital portátil, mas não tivemos a possibilidade de fazer essa gravação em espaços com isolamento acústico de tratamentos de ruído, apenas em uma sala com o mínimo de ruído possível. Vivenciamos a coleta de dados acústicos nas etapas nas quais os acadêmicos indígenas guarani e kaiowá estão presentes na Universidade Federal da Grande Dourados e interagimos com eles. Nesse ritmo, gravamos cada frase de forma natural e espontânea.

Por fim, pudemos verificar, neste trabalho, que a usabilidade do Praat, feito por meio de investigação dos dados fonéticos de palavras dos Guarani Nandéva, apesar de o software ser um dos programas de análise fonética experimental mais difundidos e acessíveis, pelos fatores que já mencionamos, ainda há a necessidade, para uso eficiente de suas ferramentas, de certo conhecimento técnico e específico de programação, pois ele não é um programa intuitivo, fato que gera dificuldades aos iniciantes que queiram fazer o uso deste software em suas pesquisas.

\section{REFERÊNCIAS BIBLIOGRÁFICAS}

ALVES, André Luis Azambuja. As características acústicas da vogal [i] do Guarani Nhandéva com o uso do PRAAT. Dissertação de Mestrado. Programa de PósGraduação em Letras da Universidade Federal da Grande Dourados. Dourados: UFGD, 2019.

BARBOSA, P. A.; MADUREIRA, S. Manual de Fonética Acústica Experimental. São Paulo: Cortez, 2015.

BARBOSA, S.; SILVA, B. Interação humano-computador. Rio de Janeiro: Elsevier, 2010.

BOERSMA, P.; HEUVEN, V. V. Speak and unSpeak with PRAAT. http: //www.fon.hum.uva.nl, 2001. Acesso em: 14 Março 2018.

BOUTSEN, F. R.; DVORAK, J. D. MATLAB ${ }^{\circledR}$ Primer for Speech Language Pathology and Audiology. San Diego, CA: Plural Publising, 2015.

COUTO, Fábio Preira. Conexões entre processos morfofonológicos e acento em Manxineru: a variedade Yine (família Aruák) falada no Brasil. Tese de Doutorado do Programa de Pós-Graduação em Linguística da Universidade de Brasília. Brasília: UnB, 2016.

CRISTÓFARO, T. Dicionário de Fonética e Fonologia. São Paulo: Contexto, 2017.

FANT, G. Acoustic Theory of Speech Production. 1. ed. Paris: DE GRUYTER, 1970.

INTERLETRAS, ISSN N 1807-1597. V. 9, Edição número 34. Outubro, 2021/ Março de 2022- p. 
HARLEY,. Visibility of System Status. nngroup, 2018. Disponivel em: <https://www.nngroup.com/articles/visibility-system-status/>. Acesso em: 25 setembro 2018.

IVO, I. Características fonéticas e estatuto fonológico de fricativas e africadas no guarani-mbyá. Dissertação (Dissertação em Linguística) - Unicamp. Campinas, p. 246. 2014.

KENT, R.; READ, C. Análise Acústica da Fala. Tradução de Alexsandro Meireles. $1^{\text {a }}$. ed. São Paulo: Cortez, 2015.

LADEFOGED, P. Vowels and consonants: an introduction to the sounds of languages. Los Angeles: Blackwell Publishing, 2007.

NASCIMENTO, M.; MAIA, M.; COUTO, L. Tempo e evidencialidade na língua Kaingang - uma abordagem experimental. revistaseletronicas.pucrs, 2016. Disponivel em: <http://revistaseletronicas.pucrs.br/ojs/index.php/fale/article/view/22543>. Acesso em: 21 outubro 2018.

NIELSEN, J. Usability Engineering. Orlando,: Academic Press, 1993.

OLIVEIRA, G. V. Língua kinikinau - Descrição de aspectos sociolinguísticos e fonológicos. Dissertação de Mestrado do Programa de Pòs-Graduação em Letras da Universidade Federal da Grande Dourados. Dourados: UFGD, 2017.

SADOWSKY,. Transcripción fonética con Praat y Lenz. sadowsky, 2013. Disponivel em: <http://sadowsky.cl/tutoriales-praat-es.html>. Acesso em: 21 setembro 2018.

SILVA, F. A sílaba em yaathe. Dissertação (Dissertação em Linguística) - UFAL. Maceió, p. 135. 2011.

SILVA, T. C. et al. Fonética Acústica: os sons do português brasileiro. $1^{a}$. ed. São Paulo: Contexto, 2019.

STYLER, W. Using Praat for Linguistic Research. wstyler, 2017. Disponivel em: <http://wstyler.ucsd.edu/praat/>. Acesso em: 16 agosto 2018.

* Doutor em Linguística. Docente da Universidade Federal da Grande Dourados, UFGD. E-mail: anderbiomartins@ufgd.edu.br.https://orcid.org/0000-0003-3216-9196

**Mestre em Linguística pela Universidade Federal da Grande Dourados. E-mail: andre.azambuja@msn.com. https://orcid.org/0000-0001-8567-428X

***Doutor em Linguística. Docente da Universidade Federal de Rondônia, UNIR, campus Ji-Paraná. Email:kgfabio@gmail.com. https://orcid.org/0000-0003-0712-6928

INTERLETRAS, ISSN N 1807-1597. V. 9, Edição número 34. Outubro, 2021/ Março de 2022- p. 